\title{
Innovation and I4.0 Management in Connected and Autonomous Automotive Manufacturing
}

\author{
Satya Shah \\ Applied Engineering and Management \\ Faculty of Engineering \& Science, University of Greenwich \\ Chatham, United Kingdom \\ s.shah@gre.ac.uk
}

Owen Mabbott

Applied Engineering and Management

Faculty of Engineering \& Science, University of Greenwich

Chatham, United Kingdom

o.mabbott@gre.ac.uk

\begin{abstract}
The paper aims to present the holistic view on the principles and practices of innovation, innovation management and industry 4.0 within connected and autonomous automotive manufacturing environments. It has been seen through literature that innovation management practices enable companies to compete within the autonomous and connected vehicle market and is considered as an emerging and competitive differentiator towards the growth of the product and that of meeting customer demands within the changing markets. Similarly, industry 4.0 has the capabilities to offer new and innovative insights within manufacturing processes, allowing organisations to exchange data across systems and enable them to utilise the information more effectively and efficiently towards future decision-making capabilities. Virtualization of the process and that of the supply ensures more smooth operations between intra-organisations and external partners and hence more advanced data sharing systems are going to be provide the functionality within the global environments. The paper examines the linkage of innovation management and industry 4.0 practices within connected and autonomous vehicles in automotive sector.
\end{abstract}

Keywords-Innovation management, information technology, connected and autonomous vehicles, I4.0

\section{INTRODUCTION}

Innovation Management enables companies to react to opportunities to launch new ideas, products and services. A trend study conducted by McKinsey revealed 'by 2020, one in five cars will be connected to the Internet [1]. Figure 1 portrays the global growth that is anticipated within the automotive industry for connected cars over traditional cars. With increased levels of growth in both connected and autonomous markets it is vital automotive companies prioritise innovation to deliver desirable products that meet customers' expectations, align with current and future trends whilst successfully gaining an edge over other competitors. With this technological innovation, there has been a distinct shift in the organisational structure of manufacturing. From the first industrial transition, from craft production to mass

\author{
Elmira Naghi Ganji \\ Applied Engineering and Management \\ Faculty of Engineering \& Science, University of Greenwich \\ Chatham, United Kingdom \\ e.naghiganji@gre.ac.uk \\ Jordan Bate \\ Applied Engineering and Management \\ Faculty of Engineering \& Science, University of Greenwich \\ Chatham, United Kingdom \\ j.bate@gre.ac.uk
}

production, the use of strict standardisation and division of labour was used to ensure uptake. The focus on customer engagement has also contributed to the need of Industry 4.0 and the use of Internet technologies. In previous industrial revolutions, production of goods has been sold in a seller's market, with the organisational structure focusing on increased output and not focusing on the customer's needs. Industry 4.0 looks to address a more customised product experience for the consumer using differentiation as markets transform into a buyer's marketplace. Industry 4.0 brings these systems together to capture the and record the large amount of data that is needed to support better decision making in the future smart factories, as well as allowing the machines to interact and share data with one another. A lean production approach is becoming more popular with Industry 4.0. This is due to the need to increase effectiveness at expanding the product variety, as well as eliminating waste along the value chain [2]. The study includes an overview of the Connected and Autonomous market, describing Innovation Management, competitor analysis across the automotive industry and the identification of other factors that contribute to competitive success. Although the literature available covers several theories, this literature review will focus on specific topics to address the question of the study.

\section{LITERATURE REVIEW}

The literature study of the paper focuses towards the key important aspect of innovation management practices and that of industry 4.0 principles within automotive manufacturing environment. The paper aims to examine understanding of best practices of adoption of the principles of innovation and technological advancements within manufacturing practices. It aims to ultimately provide the basis of establishing proposed framework to be considered by managers and leaders within manufacturing SMEs and that of supplier networks that supports automotive companies. 


\section{A. Innovation Management}

Innovation Management Topic Gateway (series No.38) published by CIMA defines innovation as 'the introduction of a new thing or method ... Innovation is the embodiment, combination or synthesis of knowledge in original, relevant, valued new products, processes or services $[3,4]$. Other simple research study highlights innovation as an outcome that is much important as that of an output. This output is ideally linked towards the introduction of new products or services and referred many a times as product innovation. Similarly, other outcomes and outputs of innovation could include process innovation, marketing innovation, business model innovation, supply chain innovation and organisational innovation [5]. CIMA emphasises the importance of companies adopting Innovation Management where competition is high, and differentiation is difficult within a given sector. The report details the different types of innovation including; Product/service innovation, Process innovation, business model innovation and marketing innovation. CIMA fails to mention how these innovation types would be used alongside each other e.g. developing a new product whilst creating an innovative marketing strategy and defining a business plan that supports the innovation. This would enable an understanding as to how innovation can cascade through a business across multiple departments not just isolated to innovating a product or service. There is a very common misunderstanding towards the definition and principles towards innovation by organisations and manufacturing companies that innovation is completely new and should be radical in nature. However, it has been noted that radical innovation is very challenging aspect in many organisations and requires special resources and one which has higher risk compared to gradual innovation. Gradual or incremental innovation is smaller aspects of innovation applied within the environment [5]. Research studies have been investigating towards the importance of innovative practices and innovation management with a key focus towards technological advancements to facilitate the growth and competitive advantage of manufacturing industries [6].

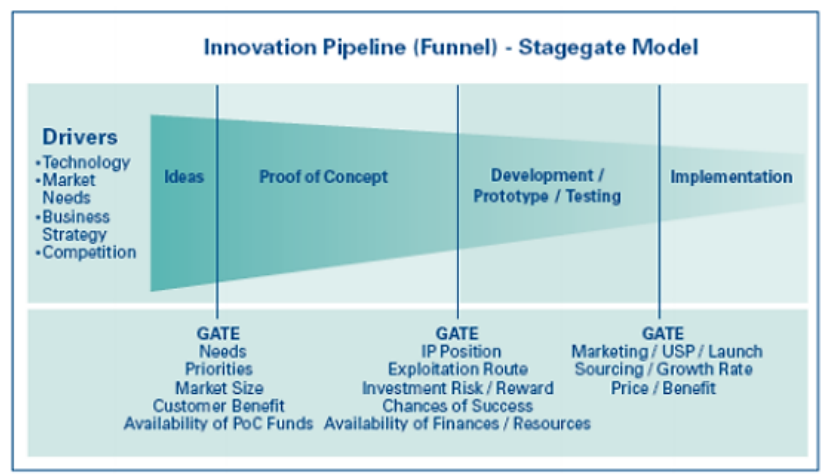

Fig. 1. D: Innovation Pipeline (Funnel) [4].

Figure 1 shows the Innovation Pipeline (Funnel) included in the CIMA report which defines the concept of moving an idea through to implementation. Whilst this model holistically portrays how to innovate, more literature is needed to understand how this would be applicable in the automotive industry for connected and autonomous vehicles. The "gating" factors within the model do not show other innovative processes and factors which may be impacted at a stage in the process e.g. e-Business, business strategy etc. These additional factors would provide a clearer understanding as to the different aspects a company may need to address in the process because of innovating a new product/service [4].

The author claims 'Innovation is both a necessary means and a desirable end for businesses in a fast-moving global economy. It is about managing a process that delivers either new products and services to the customers, efficiently, effectively and faster than the competition, or about enhancing the delivery of existing products and services by process improvement' [7]. The author describes how Innovation Management is a key enabler for companies to survive in a competitive environment, particularly within a global market. The automotive industry is mentioned as an example of where innovative processes such as production flexibility should also be implemented, aligned with new product development to increase market share and reduce production costs. The literature places focus on building close relationships between departments such as marketing and the business to ensure requirements are met for new innovative products and services.

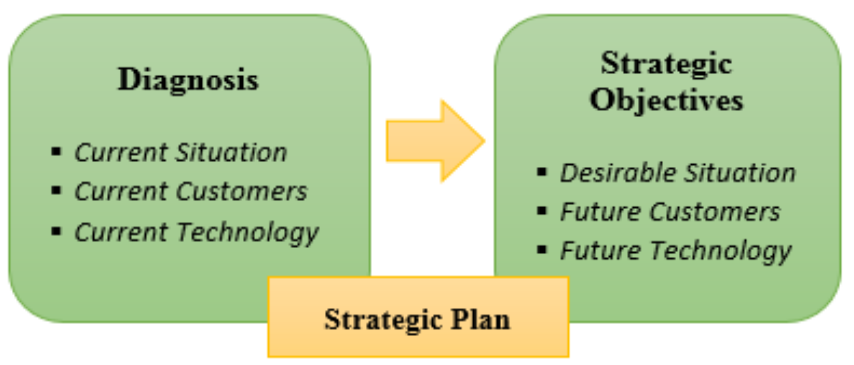

Fig. 2. Business Strategic Direction [7].

Innovative strategic planning is discussed (Figure 2) for understanding as to how an organisation can transition from their current state to an improved future state. Whilst this model makes it clear the importance of devising a plan when innovating to meet shared objectives, the literature does not show any models in terms of how relationships across different subject areas e.g. marketing, e-Business should be managed as part of Innovation Management [7]. Oliver Wyman's claim 'the leading suppliers in innovation management generate a 16 percent higher EBIT margin than their peers - all by employing a clear innovation strategy and balance along those four dimensions' [8]. The four dimensions being referred to can be seen in Fig 4, these are described as follows;

- Innovation Proposition: technological vision, customer knowledge, strategy match.

- Competence focus and collaboration: Competence focus, strategic partners. 
- Business case: Investment focus, trend focus, cost focus.

- Organisation and culture: Outside-in- strategy, people investment.

It is unclear from reading the literature the basis behind the $16 \%$ revenue and what industries/market sectors this relates to. However, the process described covers several aspects when innovating beyond the creation and implementation of the product. Whilst the study question is not specifically focusing on profitability this is a key enabler for organisations to compete within the market they are operating in or even further afield. The report details that as part of the 4-stage innovation process an innovative strategy and customer driven innovation are crucial for competitiveness. Further investigation is needed to understand how the four factors described in the innovation process work alongside product development (from having a product idea through to implementation). The report specifically focuses on the car industry which helps with applicability to the study question, however connected and autonomous vehicles are not mentioned which is an area where further research will need to be completed to understand how Innovation Management is used in these areas [8]. CIMA's report detailed various types of innovation e.g. product innovation, marketing innovation, business model innovation but treated these as separate entities in contrast to other review of literatures $[7,8]$ which are focused on close relationships across teams such as marketing and the business to support implementation of an innovative service/product. Combining different innovation processes contributed to success are described by [8], however there was no substance to the statistics mentioned. In both the literature for CIMA and Likar it is undetermined how successful their suggested approaches are. Although Likar described the importance of close relationships whilst supporting innovation there was no mention as to how this would work in practice, whereas CIMA defined how to move a product through from idea to implementation. It is also indicated how following a 4-stage process can enable organisations to compete, however it is unclear how this works in parallel with developing a product and the applicability to connected and autonomous vehicles. [8].

\section{B. Current Manufacturing Landscape}

With the need for customised consumer products, the manufacturing environment needs to change to a more complex model [9]. If it is to maintain efficiency and costeffectiveness. The use of data within a manufacturing environment is not well documented or used in practice. Although this could be considered a negative aspect, it does enable manufacturing to add new computer and networking devices to their current systems with little integration issues [10]. The innovation of new technologies has escalated industry development throughout history, from the early use of mechanised systems, to the highly automated assembly lines that are being used today. There has been exceptional growth in the usage and integration of Information
Technology within manufacturing environments since Industry 4.0 (Figure 1) has become a concept [11]. These IT systems, as well as social media platforms, have increased the influence that customers now have on the delivered product. In order to understand these innovative developments, this paper will focus on the advancement of service innovation and use of industrial data (Big Data) that is necessary for the full utilisation of Industry 4.0.

Many manufacturing-led countries, such as Germany, have made efforts to update and refresh their economy to compete with the newer, emerging markets, such as Turkey [12]. With this rising competition, manufacturers are not only focusing on manufacturing innovation, but also focus on the way they interact with their customer. Through this new outlook, the manufacturing and service industry will stimulate the development of manufacturing services [11]. The below points show the current state of manufacturing and how these services can be adapted to Industry 4.0 standards. Operator and Machine Interaction. In the current manufacturing environment, operators are in control of machines that only perform specific tasks set by a schedule $[13,14]$. Although these machines may run efficiently in today's manufacturing environment, these processes are not as efficient, or as easily managed when compared to automation. Predictability is also a growing factor through automation, being able to assess the health of machine components and tooling can lead to better cost efficiency. Within manufacturing environments, it is common to use several identical machines to perform varied tasks in different conditions. Currently, each device is supported individually in very specific conditions. The addition of sensors will allow these machines to share information that will benefit their longevity and production needs. As the output of the manufacturing process, the product's quality can provide useful information on the previous manufacturing steps, as well as machine tooling condition. This feedback of information can improve system management and improve production scheduling. In the current manufacturing environment, these kinds of feedback loops are not regularly used to their full potential and require further research.

TABLE I. COMPARISON OF TODAY'S FACTORY VS. INDUSTRY 4.0.

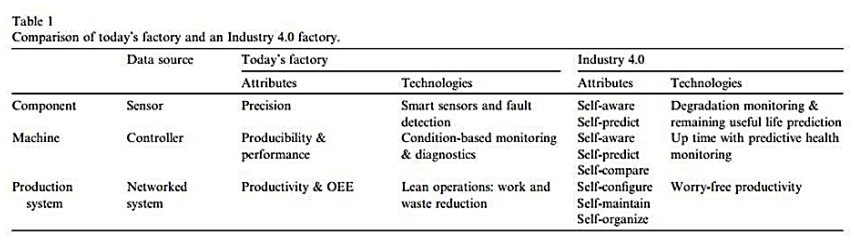

\section{Innovation and Technological Advancements}

Saul explains the importance of ensuring organisations have a business model in place that supports change and is adapted to suit the direction of the company. It is clear from this literature that companies using existing business models when innovating new products are likely to hit failure as an organisation should innovate a business model besides the 
product/services being delivered. 'The real trick is creating a business model innovation factory where technologies and capabilities can be remixed in new combinations to deliver value' [15]. In relation to if Innovation Management enables companies to compete, it would appear Saul's view is without a successful business model to support innovations competing is not possible. Whilst this literature does not specifically cover the automotive industry, the article refers to the term "netflixed". This was the case study where Blockbuster a leader in movie rentals saw the Netflix streaming service coming but failed to adapt their business model and innovate. Whilst this scenario does not reflect the connected and autonomous vehicle market, it is possible to vision a similar scenario where long established automotive companies fails to adapt their business models with companies such as Tesla entering the market, resulting in a mass decrease in market share. Saul even covers the possibility of Netflix having their market share reduced if they fail to maintain a sustainable business model. Whilst Saul details the importance of organisations becoming business model innovators no frameworks were provided as to how this would work within an innovative environment. Although Netflix was a good example and is somewhat relatable to the automotive industry in terms of market change, an example of a successful business model used to support innovation would have made this more convincing $[145$.

Researchers explored the concept of how business models will drive the future of autonomous vehicles. With many open questions such as how taxing autonomous vehicles will work, who is responsible for ethical decisions, it is anticipated these questions will be answered by business models rather than technology. There is no evidence provided in the literature to suggest business models are driving autonomous vehicles, this appears to be driven by technological innovations at the current time. Somasegar implies the market leader of autonomous vehicles will be won based on a successful business model and not necessarily technology utilisation. This is formed on the basis that there are several factors that will contribute to how customers pay for using the vehicle "For example, if regulators decide to tax autonomous vehicles based on miles travelled within a city, there will be different incentives for vehicles to stay close by to maximize trips and minimize costs" [16]. This appears to be a potential enabler for automotive companies to compete amongst each other through incorporating incentives to customers as part of their business model [16]. It is acknowledged that business models are an important aspect to enable companies to compete, with both the historical Blockbuster/Netflix example and the prospect of autonomous vehicles in the future there is no question that this is an important aspect to enable companies to compete $[15,16]$. It is believed that business models drive innovation [16] in contrast to the view that organisations should be innovators of business models to support innovative products [15]. There is a view specific to the autonomous market [16] while there are examples of failing business models shows evidence that through organisations not having innovative and flexible business models [15]. The future in the automotive market may present further opportunities such as subscriptions in vehicles which haven't been seen before so further literature should be gathered to understand how critical business models are to support the connected and automotive vehicle markets. It is explored the way how Social Media is being used to support the innovation of products from an idea phase to implementation and beyond. 'Businesses are beginning to explore how social media can help them grow and improve profits, not just with common practices such as outbound marketing, but to enhance business interactions as part of the innovation and product development process' [17].

\section{TABLE II. SOCIAL MEDIA IMPACTS ON INNOVATION [17].}

\begin{tabular}{|l|c|}
\hline Metric & Average Improvement \\
\hline Faster time to market & $16 \%$ \\
\hline Faster product adoption & $20 \%$ \\
\hline Higher market share & $6 \%$ \\
\hline Improved product revenue & $5 \%$ \\
\hline Lower product cost & $12 \%$ \\
\hline Lower product development cost & $15 \%$
\end{tabular}

Table II explains the impact social media can have at various stages throughout innovation. The author does not explain the source of these statistics but it does show how social media can be effectively used [17]. Further research is needed to address the impact of social media in product innovation to understand whether these influencing results are the case across a vast amount of markets e.g. automotive or if there are limitations. Although it is described how social media can drive product innovation through aspects such as; faster time to market, higher market share, lower product cost, and the literature fails to mention if this enables companies to compete against each other. Although lower product costs may result in companies being able to be more competitive because of using social media as part of Innovation Management, this is not clearly defined [17]. It is not also provided with any clear guidance as to where social media is best used during the innovation of products [17]. Obtaining this information would enable an understanding of how this could be linked to the connected and autonomous vehicle market. Whilst some metrics have been provided, frameworks and models as to where social media can best be used throughout Innovation Management would be more useful to reference this back to the automotive market [17].

Customer buying habits have changed in the automotive industry with the importance of dealers needing to become 'social dealers' [18]. This is the concept of dealerships using social media to connect with both an established customer base and consumers who may be interested in making a purchase. It is stated that ' $95 \%$ of car purchases begin on the 
internet (Google Consumer Study)' [18], however from checking 'think with Google' the actual statistic is 'While car sales today start online, $95 \%$ of purchases still happen at the dealership' [19] this contradiction raised some questions as to the validity of the data initially mentioned. Kruse mentions the importance of ensuring social media is used not necessarily from a marketing perspective but ensuring automotive companies understand customers' needs aligned with trends. It is clear if automotive companies fail to factor in social media as part of innovating new products there is a concern consumers' needs will not be met. Whilst it is apparent social media needs to form part of product innovation, it was unclear from the literature where this is best placed in a process and how it enables companies to compete effectively, particularly in the expanding connected and autonomous vehicle market [18].

'While many companies are familiar with using social media for outbound marketing and communication efforts, leveraging social media for innovation is a new concept for most' [20]. The author stresses the importance of using social media as part of product innovation and describes how this is a new concept. It raises the question as to if automotive companies are reaching out to customers as part of the development of connected and autonomous vehicles. This ensures that customers' requirements are understood whilst also managing to gain an edge over competitors in instances where other companies are not doing so or are not as effective. Biase explains in detail how social media is best leveraged in an innovative product lifecycle and the concept of it being used as ideas are initiated with proof of concepts being created to test against customer's needs. Whilst this literature is not specific to the connected and autonomous vehicle market, gathering research around if customers are currently engaged via social media in this area as this may provide a suitable recommendation going forward to ensure customers' needs are met [20]. It is explained how social media can be a positive enabler in product innovation in many areas such as; faster product adoption and go to market timing [17] whereas other authors focus on the influence social media can have in the early days of product innovation [18,19]. Although the importance of using social media in such an early part of product innovation is emphasized [18], it was not clear how this would be defined in a product innovation process. Details on how social media can be leveraged specifically at phases in the product innovation process [20], however this was not applicable to the connected and autonomous vehicle market whereas another study from a sector perspective was more relevant [18]. The introduction of social media early into the product innovation process is described as "new" [20] whereas other authors imply this is being adopted more and more by companies [17,18]. The literature from [20] dates to 2015 so that could be a potential factor of this being a new adoption at the time it was written. Literature around the current state of social media in product development within the automotive industry would assist in providing more insights as to how this can be used to support innovation management.

\section{Big Data and IoT in Manufacturing}

The sheer amount of data that is created and distributed within a manufacturing environment are not utilised in an effective and efficient way. Industry 4.0 is steering manufacturing to smarter environments and machines, which are self-learning and self-aware and able to make decisions based on collected data. These kinds of smart algorithms do not currently exist and require further research and development if they are to be utilised in a manufacturing environment. The latest buzzword in the IT community is "Big Data". With many devoted researchers to this area, the idea of data-driven organisations is becoming more prevalent in the manufacturing sector. Mostly focusing on data mining, the current research considers the use of data for sales predictions, recommendation systems and opinion decision making.

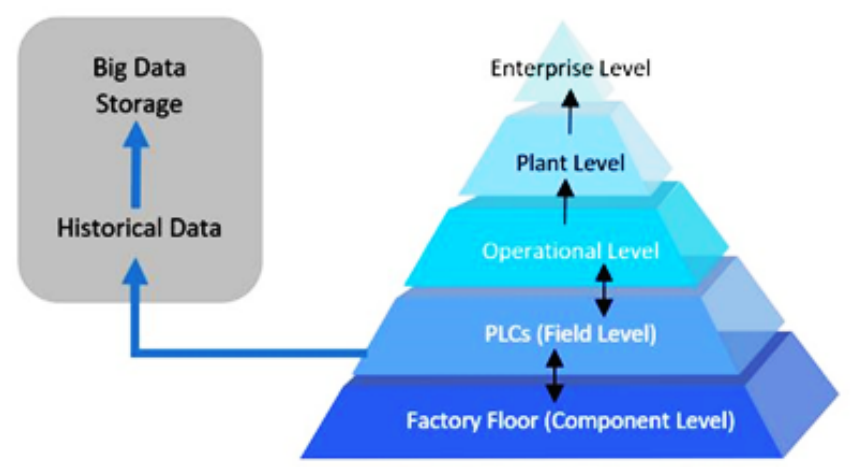

Fig. 3. Big Data Organisational Fit.

The idea that manufacturing machines can predict problems ahead of time and then manage themselves better is a positive for all manufacturing environments. The use of this data and technology will help improve the production efficiency, as well as reduce production costs. An example of this can be tooling machines that need to have regular maintenance, by utilising big data technologies, information will be gathered on the use of the tooling, to then recommend when the parts need to be serviced or replaced. This would improve end-product quality, as well as more efficient production running as the machines can be scheduled for service, rather than guessing when the maintenance needs to be carried out, or the machine fails. As per the above comments, the Industry 4.0 concept brings together intelligent analytics and CPS to create a new era of production management and thinking. Through the correct usage of networked sensors, data can be collected based on collected vibration and pressure information. Historical data can also be brought in for additional data mining. Figure 3 shows where Big Data fits within the organisational structure. Operating on the field level, it collects the data from the factory floor devices and is then stored on data servers, used for big data analysis. This information is then shared through the organisational levels, up to the top tier enterprise level. 


\section{E. Technology Advancements in Automotive Manufacturing}

Studies explains how technology is transforming the automotive industry providing more opportunities to automotive companies. 'Research from the RAC shows that cars actually sit unused on our driveways 96 per cent of the time' [21]. Whilst connected and autonomous vehicles are the main areas of focus for many automotive companies, studies explain using technology beyond the vehicle such as car sharing that consumers can connect with via mobile apps will provide additional revenue for companies. Further to the transformation technology is having within the automotive industry, studies explains that with car sharing schemes becoming more popular over vehicle ownership this provides a market for automotive companies to compete in beyond innovating new connected and autonomous vehicles. The $\mathrm{CEO}$ at the rental company EasyCar Club so generally refers to the embracement of technology from a car sharing/renting perspective as this is closer aligned to his business rather than the full market picture. Nevertheless, the view provided shows how automotive companies can compete with competitors beyond vehicle technology to provide additional services like car sharing [21].

A study shows the technology car manufactures are embracing in their prototype vehicles to support autonomously [22]. It explains that with technology changing faster than ever before it is difficult for car manufacturers to remain competitive with technology being out dated in vehicles prior to even being launched. 'The automotive industry spends around $€ 77$ billion worldwide on R\&D to nurture innovation and to stay competitive' and the author suspects this is only going to increase in the connected and autonomous world with those companies ploughing in the most money being able to leave competitors behind [22] Connected and Autonomous vehicles technology also have many legal and security constraints with these being described as 'serious issues to be addressed'. Whilst technology is making connected and autonomous vehicles possible, the constraints Bagloee has identified mean that competing with ever evolving technology may result in automotive companies struggling to compete against competitors when innovating new products. Studies identifies several constraints about technology with less of a focus on opportunities. However, from a competitor perspective it identifies where some companies may be able to accelerate in contrast to others [22].

Similar studies view that technology is an enabler for automotive companies to provide services such as car sharing, shows the opportunity that the innovation of connected and autonomous cars presents. In contrast, Bagloee describes several constraints that automotive companies may face because of technology changes e.g. faster innovative pace, legal battles without so much of a focus on opportunities. Combining both authors views there is a wide range of technology available to support connected and autonomous vehicles, with the study looking at the use of technology to provide additional services whilst Bagloee is looking more at the vehicle technology itself. Research around consumers' requirements would enable a clearer understanding as to whether the opportunities technology presents such as through providing car sharing services will enable a competitor to stand-out over a company focusing on technology within the vehicle.

\section{F. Connected and Autonomous Products}

Connected and autonomous vehicles are defined as 'A connected vehicle is a vehicle with technology that enables it to communicate and exchange information wirelessly with other vehicles, infrastructure, other devices outside the vehicle and external networks' [23]. An autonomous vehicle is a vehicle that is, in the broadest sense, capable of driving itself without human intervention' [23]. With SMMT clearly defining the difference between Connected and Autonomous vehicles, it appears 'Connected Vehicles' can be seen more as the current/immediate state with 'Autonomous' vehicles expected to provide a number of technological features in the future.

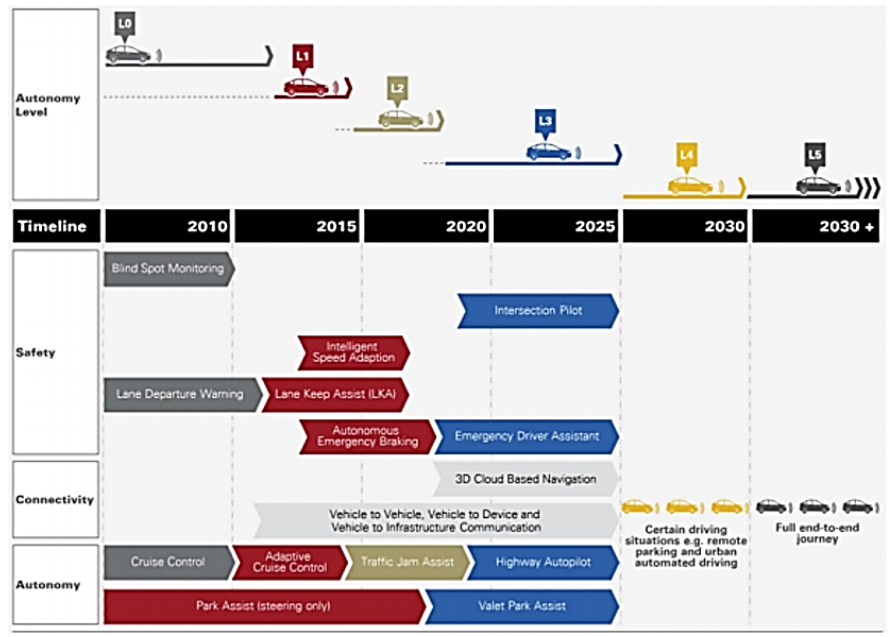

Fig. 4. Connected and Autonomous Vehicles Technology Roadmap [23].

Figure 4 indicates the anticipated roadmap for connected and autonomous vehicles with automotive companies already incorporating some of the corresponding technology available into vehicles. The SMMT report covers connected and autonomous vehicles from a UK perspective addressing issues such as network coverage. Although this information is useful, a global report would help to understand international constraints beyond the UK as the report has identified barriers to technology, infrastructure, legal considerations which may affect how well automotive companies can compete in the UK for this sector [23]. Comments from Marcus Rothoff are included within literature, Volvo's autonomous driving program director reasons why Volvo has scaled back its self-diving car experiment 'We are finding that there were more issues to dig into and solve than we expected' [24]. It is also explained when Volvo initially announced their self-driving car 
experiment they were trying to compete with competitors such as Tesla, GM, Mercedes-Benz, and Audi but after hitting numerous barriers including issues with architecture in the vehicles the initial proposed timing had to be amended [24]. The article does not mention if Volvo were using Innovation Management to drive their self-driving car projects. Obtaining this information would help to understand what factors beyond technical problems led to Volvo committing to a plan to compete with their competitors but not being able to deliver. Hawkins states how other car manufacturers already have got the proposed technology available in vehicles, raising the question what the key differences between Volvo and other competitors that are impacted Volvo's ability to compete in the same market at the same time [24].

Strategy\& states in their report 'clearly, the traditional carmakers and suppliers need to significantly accelerate their transformation capability. Their current rate of innovation is too slow to keep up with all the new players entering the field' [25]. Strategy \& describes how some automotive companies such as Tesla and are being able to innovate through maximising technology in contrast to other automotive companies which are struggling. Strategy\& does not mention the automotive companies which cannot innovative at the pace of competitors, this information would be useful to investigate how they are strategically managing innovation in the connected and autonomous market. The report dates to 2016 so it is possible competitors which could not meet progress from companies such as BMW and Tesla have been able to step up to the competition, however further literature would need to be obtained [25]. It is focused on UK market and progression with autonomous and connected vehicles [23], whilst other authors more competitor specific, identifying instances where automotive companies could not maintain the market pace [24,25] SMMT identified constraints in the UK which could impact brands deemed to be succeeding such as Tesla and BMW but it is unclear from the literature what markets brands are targeting as to those which are the most lucrative from a trends and connectivity perspective. It is not specifically mentioned what brands were struggling to innovate in comparison to succeeding competitors [25], it can be assumed from [24] that Volvo is likely to be one company being referred to here, but a deeper understanding around this would enable further research to be obtain perhaps identifying failing Innovation Management strategies.

\section{RECOMMENDATIONS AND FUTURE RESEARCH}

Through reviewing literature across several innovative factors such as business models, social media, product development, technology, marketing it is clear there are numerous approaches that should be considered to support innovation. It remains unclear whether automotive companies within the connected and autonomous vehicle market would classify the innovative factors researched as
"Innovation Management" or not. From the literature reviewed these factors such as marketing do not always seem to fall under Innovation Management with examples provider of innovative marketing being carried out, undermining a new product. It was seen under technology, instances where opportunities are presented but it is questionable if automotive companies recognise these if focusing on connected and autonomous vehicles under Innovation Management rather than looking further afield at arising opportunities. Literature obtained regarding Connected and Autonomous vehicles showed some automotive companies were being left behind by competitors but it is unclear the differentiating factors such as the Innovation Management strategies across companies. The data showed that UK had constraints with infrastructure amongst other problems which raises the question are even those brands which were described as leading the competition able to adapt to meet changing requirements and remain on top [23].

Further research is required to understand automotive company's current approach to innovation management, identifying how this aligns with the information obtained in this literature review. Through the literature reviewed, closing the gaps identified and carrying out further research this should enable suitable recommendations to be made to answer the study question towards the concepts of innovation management and that of industry 4.0 principles and practices towards wider enhancement of the automotive sector, particularly focusing towards connected and autonomous vehicles market.

This paper has provided an overview on the important aspect of innovation management and that of industry 4.0 principles and practices adoption within connected and autonomous vehicles within automotive manufacturing companies. It has been evident through our research study that many researchers aim towards investigating technical and engineering perspectives towards technology adoption and technological advancements, whereas the key aspect of innovation management practices are not fully explored. The paper also examines the role of industry 4.0 and how companies, especially that of automotive manufacturers have started to adopt advanced technological tools within the respective environments. Similarly, it has been investigated through our research that innovation management can further be expanded towards the development, production and marketing integration on wider supply chain aspects of the organisation. This further facilitates the end user satisfaction measures of the product and service environments, especially within the connected and autonomous automotive markets.

The authors of this research aim to further develop a novel framework that will facilitate the potentials of market innovation with the use of technology application, including the linkage between these concepts to that of product and service innovation projects within the global automotive manufacturing environments. 


\section{CONCLUSIONS}

From reviewing a range of literature across subject areas it has supported addressing the research question whether if innovation management is successfully enabling companies to compete in the connected and autonomous vehicle markets. Literature studies on innovation management demonstrated there were many processes which could be followed by companies to move products from an idea through to implementation. Similarly, the paper presented that industry 4.0 principles proposes the next revolutionary step towards simplifying the manufacturing process, using predictive manufacturing and data mining practices. With these practices, organisations can enhance their current machining process to be more intelligent machines with having self-awareness capabilities to allow a more collaborative community. Our study aims to simply understand the concepts while focusing on the current state of manufacturing environments aims to compare industry 4.0 standards and its applications towards wider concepts of automotive manufacturing and that of the factories of future principles. Finally, the paper aims to utilise the concepts of big data and IoT with the opportunities that it offers to organisations. Though there may not be strict standards addressing the industry 4.0 concepts, the technology enables different organisations to differentiate and customise their production activities to meet the demands of the market. Hence, industry 4.0 leaders mainly within larger manufacturing industries and organisation are currently using different tools and methodologies to deliver the same essential services towards product and service function of the environment. This is further achieved with the use of intelligent automation techniques and the reorganisation and reschedule of workforce within the entire production system. These manufacturing environments will further thrive towards advanced self-organising systems that is able to detect and rectify faults and failures earlier before they impact production while boosting performance and reducing overall production costs.

\section{REFERENCES}

[1] GTAI (2016) The Automotive Industry in Germany, Germany: Germany Trade \& Invest.

[2] M. Brettel, N. Friederichsen, M. Keller, and M. Rosenberg, "How Virtualization, Decentralization and Network Building Change the Manufacturing Landscape: An Industry 4.0 Perspective," World Academy of Science, Engineering and Technology, International Journal of Mechanical, Aerospace, Industrial, Mechatronic and Manufacturing Engineering, 8(1), pp.37-44, 2014.

[3] R. Luecke, and R. Katz, Managing Creativity and Innovation. Boston, MA: Harvard Business School Press. ISBN 1-59139$112-1,2003$

[4] J. Downey, Innovation Management Topic Gateway Series No. 38, United Kingdom: The Chartered Institute of Management Accountants, 2007.

[5] K.B. Kahn, "Understanding innovation," Business Horizons, 2018

[6] D. Kralisch, D. Ott, A.A. Lapkin, P. Yaseneva, W. De Soete, M. Jones, N. Minkov, and M. Finkbeiner, "The need for innovation management and decision guidance in sustainable process design," Journal of Cleaner Production, 172, pp.23742388,2018

[7] B. Likar, Innovation Management, Slovenia: Korona plus d.o.o., Institute for Innovation and Technology, 2013.

[8] Oliver Wyman. 2015 Car Innovation, Germany: Oliver Wyman, 2015.

[9] V. Vyatkin, Z. Salcic, P.S. Roop, and J. Fitzgerald, "Now That's Smart!," Industrial Electronics Magazine, IEEE, 1(4), pp.7-29, 2007.

[10] E. Abele, A. Wörn, J. Fleischer, J. Wieser, P. Martin, and R., Klöpper, "Mechanical module interfaces for reconfigurable machine tools," Production Engineering, 1(4), pp.421-428, 2007.

[11] J. Lee, H. Kao, and S. Yang, "Service Innovation and Smart Analytics for Industry 4.0 and Big Data Environment," Procedia CIRP, 16, pp.3-8, 2014.

[12] Y. Luo, and J. Bu, "How valuable is information and communication technology? A study of emerging economy enterprises," Journal of World Business, 51(2), pp.200-211, 2016.

[13] I. Einsiedler, "Embedded Systeme für Industrie 4.0," Product. Management, 18, pp.26-28, 2013.

[14] R. Achatz, K. Beetz, M. Broy, H. Dämbkes, W, Damm, K. Grimm, and P. Liggesmeyer, "Nationale Roadmap Embedded Systems," ZVEI-Zentralverband Elektrotechnik-und Elektronikindustrie eV Kompetenzzentrum Embedded Software \& Systems, 2009.

[15] K. Saul, The Business Model Innovation Factory: How to Stay Relevant When The World is Changing, 1st edn., Canada: Wiley, 2012.

[16] S. Somasegar, "Business models will drive the future of autonomous vehicles". [Online]. Available at: https://techcrunch.com/2017/08/25/business-models-willdrive-the-future-of-autonomous-vehicles/ (Accessed: 23rd January 2018), 2017.

[17] A. Kenly, and B. Poston, "Social media and product innovation: early adopters reaping benefits amidst challenge and uncertainty," A Kalypso White Paper. Kalypso, 2014.

[18] K. Kruse, Automotive Social Business 2.0: How to Captivate Your Customers, Sell More Cars and Be Generally Remarkable on Social , 2nd edn., United States of America: CreateSpace Independent Publishing Platform, 2016.

[19] D. Evans, How Hyundai Changed Course to Improve the Customer Journey, Available at: https://www.thinkwithgoogle.com/marketingresources/experience-design/hyundai-car-shopping-customerjourney/ (Accessed: 23rd January 2018), 2017.

[20] S. Biase, Applied Innovation: A Handbook, 1st edn., United States of America: Premier Insights, 2015.

[21] R. Laughton, How Technology is Transforming the Automotive Industry, Available at: https://www.virgin.com/entrepreneur/how-technologytransforming-automotive-industry (Accessed: 21/1/2018).

[22] S. Bagloee, and M. Tavana, "Autonomous Vehicles: Challenges, Opportunities, and Future Implications for Transportation Policies," Journal of Modern Transportation, 24(4), pp.284-303, 2016.

[23] KPMG International, SMMT, Connected and Autonomous Vehicles - The UK Economic Opportunity, 2017.

[24] A. Hawkins, Volvo is Reportedly Scaling Back its Ambitious Self-Driving Car Experiment, https://www.theverge.com/2017/12/14/16776466/volvo-driveme-self-driving-car-sweden-delay / (Accessed: 23rd January 2018), 2017.

[25] Strategy\& (2016) Connected Car Report, United Kingdom: Strategy\&. 